\title{
Nova espécie de Cybianthus Mart. (Myrsinaceae) do sudeste do Brasil
}

\author{
Sigrid Luiza Jung-Mendaçolli ${ }^{1,3}$, Luís Carlos Bernacci ${ }^{1}$ e Maria de Fátima Freitas ${ }^{2}$
}

Recebido em 8/01/2008. Aceito em 4/03/2010

RESUMO - (Nova espécie de Cybianthus Mart. (Myrsinaceae) do sudeste do Brasil). Descrevemos e ilustramos uma nova espécie de Cybianthus (Myrsinaceae) do sudeste brasileiro: Cybianthus membranaceus Jung-Mend., Bernacci \& M.F.Freitas, que é próxima de Cybianthus cuneifolius Mart., mas pode ser facilmente distinta pelas inflorescências muito mais curtas que a lâmina foliar e folhas obovais ou oblanceoladas, tenuemente membranáceas, com ápices obtuso-cuspidados, concentradas na porção distal dos ramos.

Palavras-chave: Cybianthus, espécie nova, Myrsinaceae, Mata Atlântica

ABSTRACT - (New species of Cybianthus Mart. (Myrsinaceae) from southeastern Brazil). We described and illustrated a new species of Cybianthus Mart. (Myrsinaceae) from southeastern Brazil: Cybianthus membranaceus Jung-Mendaçolli, Bernacci \& M.F.Freitas, that is similar to Cybianthus cuneifolius Mart., but can be easily distinguished by the inflorescences that are much shorter than the leaf blade, plus the thin membranaceous, obovate or oblanceolate leaves, with obtuse-cuspidate apices and concentrated in the distal portion of the branches.

Key words: Cybianthus, new species, Myrsinaceae, Atlantic Forest

\section{Introdução}

O gênero Cybianthus Mart. (Myrsinaceae) tem distribuição neotropical, sendo-lhe atribuído cerca de 160 a 170 espécies, em 10 subgêneros (Agostini 1980; Pipoly 1981; 1987; Pipoly \& Ricketson 2006). Cybianthus pode ser diagnosticado pelas inflorescências axilares, não congestas (variando de racemosas a paniculadas, espiciformes ou em pleiocásio); flores gamossépalas e gamopétalas; estames epipétalos, com ou sem filetes, sendo estes mais curtos do que a corola e adnatos a ela, formando ou não um tubo estaminal.

No Brasil, o gênero Cybianthus foi pouco estudado, destacando-se as obras de Miquel (1856) e Mez (1902), somando-se, ao final deste primeiro período 19 espécies relatadas para o sudeste. Posteriormente, o número de espécies conhecidas de Cybianthus para o sudeste do Brasil foi elevado por Joly \& Jung (1978), que descreveram $C y$ bianthus coronatus A.B.Joly \& Jung-Mend., e por Agostini (1980) que estabeleceu uma circunscrição mais ampla para o gênero, transferindo as espécies anteriormente incluídas em Conomorpha A.DC. e Weigeltia A.DC., das quais seis do sudeste. Pipoly (1993) referiu uma nova espécie, $C y$ bianthus rupestris Pipoly, como sendo do sudeste brasileiro, entretanto, indicou que a mesma é endêmica da Chapada dos Veadeiros (Goiás), que, na realidade, não se localiza no sudeste e sim no Brasil Central, tendo havido um equívoco quanto à interpretação geográfica por parte do descritor. Simultaneamente, Pipoly (1993) sinonimizou Cybianthus glaziovii Mez, reduzindo, então, o número de espécies conhecidas de Cybianthus ocorrentes no sudeste brasileiro para 25 espécies.

Agostini (1980) reconheceu 10 subgêneros para o gênero Cybianthus (sensu lato), considerando que o tipo de inflorescência, número de elementos e tipo de indumento da flor, tipo de inserção, relação entre a altura e largura e tipo de deiscência das anteras eram úteis para delimitar as espécies originalmente descritas no gênero Cybianthus (Cybianthus sensu stricto) como constituintes do subgênero Cybianthus, por ele proposto. Os subgêneros Cybianthus (cerca de 50 espécies), Conomorpha e Weigeltia (cerca de 40 espécies, cada) e Laxiflorus e Triadophora têm representantes no Brasil, os dois últimos, exclusivamente na Amazônia (Agostini, 1980). O centro de diversidade do subgênero Conomorpha localiza-se nas Guianas e Weigeltia não tem um centro de diversidade bem definido ou conhecido, enquanto 30 espécies do subgênero Cybianthus ocorrem no território brasileiro, especialmente no sudeste, que abriga 18 espécies deste subgênero. Ainda, a circunscrição do gênero Cybianthus chegou a ser ampliada posteriormente (Pipoly 1987), com base em uma análise filogenética, com a inclusão das espécies com flores hermafroditas, originalmente, descritas no gênero Grammadenia. Na mesma ocasião, Pipoly (1987) sinonimizou o subgênero Iteoides ao subgênero Microconomorpha. Finalmente, Anderberg \& Ståhl (1997) e Ståhl (1997), utilizando uma espécie não identificada de Grammadenia e Conomorpha peruviana, reconheceram, através de análises filogenéticas, que a inclusão de Grammadenia torna polifilético o gênero Cybianthus (sensu Pipoly 1987).

Jung (1981), Jung-Mendaçolli \& Bernacci $(1997 ; 2001)$ e Jung-Mendaçolli et al. (2005) apresentaram detalhes taxonômicos de espécies de Cybianthus, em estudos regionais para as Myrsinaceae. Jung-Mendaçolli \& Bernacci (2001) e Jung-Mendaçolli et al. (2005) reconheceram materiais como de uma possível espécie inédita, entretanto, a escassez de amostras e a limitação da abrangência geográfica impossibilitaram a efetiva publicação da espécie. Com o prosseguimento dos estudos para a família no Brasil e análise de materiais botânicos de outras localidades, esta nova espécie é enfim descrita, recebendo a denominação de C. membranaceus, em razão de suas folhas tenuemente membranáceas.

\footnotetext{
Instituto Agronômico, São Paulo, SP, Brasil

2 Instituto de Pesquisas Jardim Botânico do Rio de Janeiro, Diretoria de Pesquisa Científica, Rio de Janeiro, RJ, Brasil

3 Autor para correspondência: jungmend@iac.sp.gov.br
} 


\section{Material e métodos}

Os espécimes de Cybianthus coletados no estado de São Paulo e na APA de Cairuçu (Parati - RJ) dos acervos dos herbários BAUR, BOTU, ESA, FCAB, HB, HPL, HRCB, IAC, PMSP, R, RB, SJRP, SP, SPF, SPFR, SPSF, UEC e UNBA, foram comparados com os exemplares de outras localidades, para proceder à identificação das espécies, chegando-se ao reconhecimento de uma nova espécie de Cybianthus, aqui descrita.

\section{Resultados e discussão}

Cybianthus membranaceus Jung-Mend., Bernacci \& M.F.Freitas sp.nov.

Fig. 1A-E.

Cybianthus membranaceus Jung-Mend., Bernacci \& M.F.Freitas C. cuneifolio affinis, sed foliis obovatis vel oblanceolatis, membranaceis, congestis ad extremitates ramorum, apice obtuso vel cuspidato et inflorescentiis foliis brevioribus differt.

Arbusto ca. $8 \mathrm{~m}$ alt.; ramos 1,5-3 mm diâm., com tomento ferrugíneo nas partes jovens, glabros na maturidade, casca marrom. Folhas concentradas no ápice dos ramos; pecíolo (2-)3-6 mm; lâmina (7-)10,4-15,4 x (2,7-)3-4,1(-4,8) cm, tenuemente membranácea, obovada ou oblanceolada, ápice obtuso, cuspidado, base aguda ou atenuado-acuminada, pontuações glandulares ferrugíneas, marrons ou negras em ambas as faces, glabra e com canais resiníferos visíveis na face adaxial, tomento ferrugíneo na face abaxial, apenas em folhas jovens; nervuras secundárias 9-13, ascendentes, delicadamente proeminentes, intercaladas pelas de menor ordem, em ambas as faces. Inflorescência estaminada (0,9)1,9-4,4 x 0,6-1,2 cm, racemosa, laxa, ereta, muito mais curta do que a lâmina foliar; pedúnculo $0,5-2,2 \mathrm{~cm}$, tomento glanduloso, ferrugíneo; brácteas ca. $1 \mathrm{~cm}$, lineares, ápice agudo. Flores estaminadas 4-meras; brácteas florais 1-1,5 $\mathrm{mm}$, linear-lanceoladas; flores masculinas com pedicelo 1-2,3 mm; cálice ca. 2,3 mm diâm., 1/5 unido, lobos ca. 0,8 x $0,7 \mathrm{~mm}$, ovais, ápice agudo ou arredondado, glândulas vinosas arredondadas, margem com tricomas glandulares, ferrugíneos; corola esbranquiçada, ca. 5,0 mm diâm., rotada, 1/3 unida, hialino-lepidota na face adaxial, lobos ca. 1,9 x 1,9 mm, oblongos a suborbiculares, ápice arredondado, glândulas vinosas arredondadas, margem com tricomas lepidoto-hialinos; anteras ca. $0,5 \mathrm{~mm}$, ovais, base cordada, ápice muito agudo, basifixas, com pontuações acima do ponto de inserção, filete ca. $0,4 \mathrm{~mm}$, anel estaminal não evidente; pistilódio ca. 0,6 x 0,4 mm, cônico, estigma inconspícuo; inflorescências e flores pistiladas não vistas. Fruto ca. $7 \mathrm{~mm}$ diâm., imaturo verde, apículo caduco; sementes ca. 5 x 5 $\mathrm{mm}$, arredondadas.

Tipo: BRASIL. Rio de Janeiro: Parati, Morro do Carrapato, 200 m.s.m., 17/IV/1994, fr., R. Marquete 1669 (Holótipo RB; Isótipo IAC).

Parátipos: BRASIL. São Paulo: Caraguatatuba, 17/I/1990, fl., M. Imamoto s.n. (SPSF 13294). Ubatuba, Estação Experimental do IAC - Instituto Agronômico, 16/X/1979, fl., J.Y. Tamashiro \& A.F. Silva 211 (RB, UEC).

Cybianthus membranaceus assemelha-se a Cybianthus cuneifolius Mart. diferindo principalmente pelas folhas tenuemente membranáceas, obovadas ou oblanceoladas com ápice obtuso-cuspidado, concentradas na porção distal dos ramos, e inflorescências estaminadas muito mais curtas do que as folhas (Tab. 1). Enquanto as inflorescências estaminadas ou pistiladas de $C$. cuneifolius têm cerca da metade até $70 \%$ do comprimento da lâmina foliar, as inflorescências estaminadas de C. membranaceus têm apenas $10 \%$ até $1 / 3$ do comprimento da lâmina foliar (não foi possível examinar inflorescências pistiladas desta última).

O gênero Cybianthus foi estabelecido por Martius (1829) e distinto dos demais pela dioicia, corola rotácea e anteras transversalmente deiscentes. Agostini (1980) apoiou sua circunscrição mais ampla, para Cybianthus, nas muitas semelhanças com as espécies dos gêneros Conomorpha e Weigeltia, considerando que apenas o tipo de inserção e a

Tabela 1. Características diferenciais entre Cybianthus membranaceus Jung-Mend., Bernacci \& M.F.Freitas e Cybianthus cuneifolius Mart.

\begin{tabular}{|c|c|c|}
\hline Característica & C. membranaceus & C. cuneifolius \\
\hline Distribuição das folhas & concentradas na porção distal do ramo & ao longo de todo o ramo \\
\hline Forma da lâmina foliar & obovada ou oblanceolada, não decurrente no pecíolo & $\begin{array}{l}\text { lanceolada, elíptico- lanceolada às vezes obovado- } \\
\text { lanceolada, decurrente no pecíolo }\end{array}$ \\
\hline Consistência da lâmina foliar & tenuemente membranácea & membranácea a rígido-membranácea \\
\hline Base foliar & aguda ou atenuado-acuminada & longamente atenuado-acuminada \\
\hline Ápice foliar & obtuso-cuspidado & longamente atenuado-acuminado. \\
\hline Comprimento do pecíolo & $(2-) 3-6 \mathrm{~mm}$ & $4-14 \mathrm{~mm}$ \\
\hline Comprimento da lâmina foliar & $(7-) 10,4-15,4 \mathrm{~cm}$ & $7-18 \mathrm{~cm}$ \\
\hline Comprimento da inflorescência & $(0,9-) 1,9-4,4 \mathrm{~cm}$ & $(1,5-) 3,8-8,5 \mathrm{~cm}$ \\
\hline $\begin{array}{l}\text { Relação entre o comprimento da } \\
\text { inflorescência e da lâmina foliar }\end{array}$ & $0,1-0,3$ & $0,5-0,7$ \\
\hline Pedicelo da flor masculina & $1-2,3 \mathrm{~mm}$ & ca. $6 \mathrm{~mm}$ \\
\hline Estames & com filetes ca. $0,4 \mathrm{~mm}$ & Sésseis \\
\hline
\end{tabular}




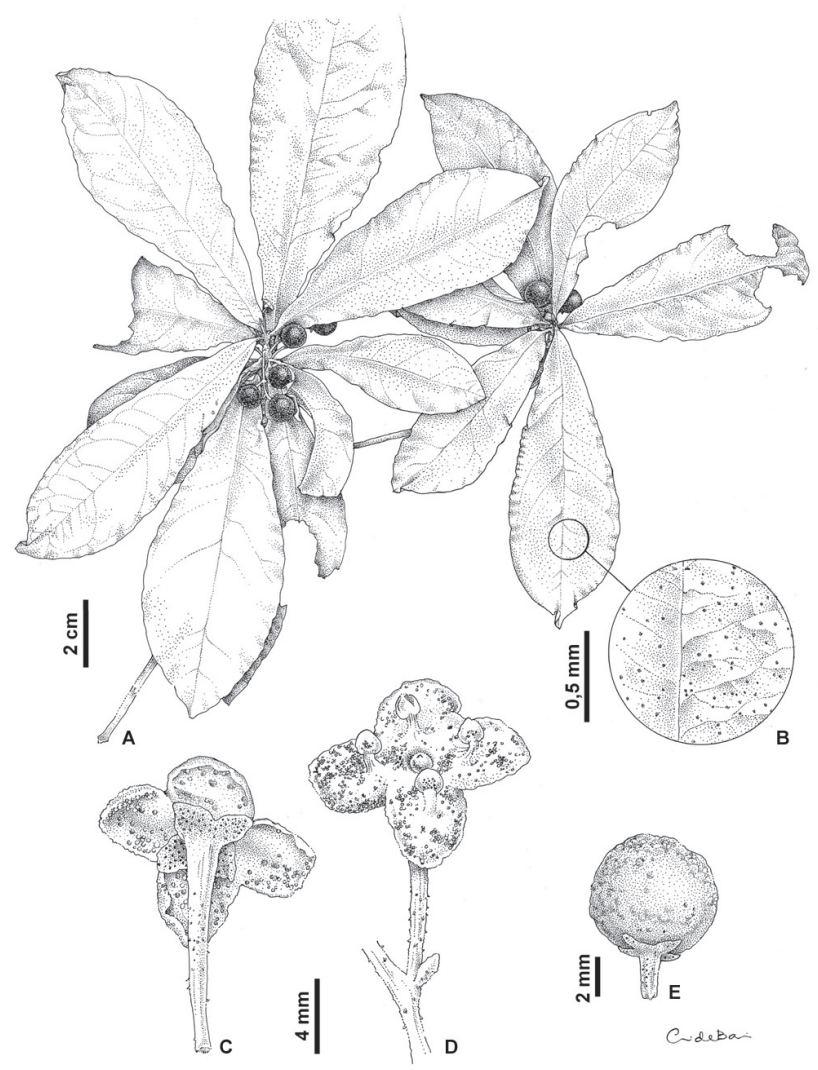

Figura 1. A-E. Cybianthus membranaceus Jung-Mend., Bernacci \& M.F.Freitas: A. ramo em frutificação; B. detalhe da face adaxial da lâmina foliar; C. flor evidenciando cálice e corola; D. flor evidenciando corola, androceu e pistilódio; E. fruto. A, B, E: R. Marquete 1669 - IAC e RB; D: J.Y. Tamashiro \& A.F. Silva $211-\mathrm{RB}$ e UEC.

relação entre a altura e largura das anteras, eram inconsistentes para separá-las em gêneros distintos. De acordo com os sistemas de classificação propostos por Agostini (1980) e Pipoly (1987), Cybianthus membranaceous Jung-Mend., Bernacci \& M.F.Freitas pertence ao subgênero Cybianthus.

Até o momento, existem registros de coletas desta nova espécie apenas entre os municípios limítrofes do litoral norte do estado de São Paulo (Caraguatatuba e Ubatuba) e litoral sul do Rio de Janeiro (Parati). Assim, C. menbranaceus deve ser considerada como endêmica das florestas ombrófilas densas da Mata Atlântica, entre cerca de 40 a $200 \mathrm{~m}$ de altitude, em uma pequena região entre estes dois estados do sudeste brasileiro. Embora tenha uma área de ocorrência conhecida restrita (de acordo com os critérios da IUCN 2001), de cerca de $1500 \mathrm{~km}^{2}$, por ter registros de ocorrência em unidades de conservação (APA - Área de Proteção Ambiental - de Cairuçu e Parque Estadual da Serra do Mar - Núcleo Caraguatatuba), se encontra relativamente protegida, por estar sob menor pressão antrópica, não devendo sofrer declínios populacionais significativos, assim, não deve estar ameaçada de extinção. Entretanto sua população deve ser mais bem observada, em situação de campo, já que declínios populacionais representarão a sua inclusão na categoria em perigo.

\section{Agradecimentos}

Agradecemos aos curadores dos herbários SPSF, UEC, RB e IAC, pelo empréstimo dos materiais utilizados para a descrição; ao Dr. Jorge Fontella Pereira, do Museu Nacional do Rio de Janeiro, pela diagnose latina, e à ilustradora Ana Carolina de Bassi, pela confecção da ilustração.

\section{Referências bibliográficas}

Agostini, G. 1980. Una nueva clasificación del género Cybianthus (Myrsinaceae). Acta Botanica Venezuelica 10: 129-185.

Anderberg, A.A. \& Ståhl, B. 1997. Phylogenetic interrelationship in the order Primulales, with special emphasis on the family circumscriptions. Canadian Journal of Botany 73: 1699-1730.

IUCN - International Union for Conservation of Nature and Natural Resources. 2001. IUCN Red List Categories and Criteria version $3.1 \mathrm{http}: / /$ www.iucnredlist.org/technical-documents/categories-andcriteria/2001-categories-criteria\#critical (acesso em 15/01/2010).

Joly, A.B. \& Jung, S.L. 1978. Cybianthus coronatus Joly et Jung sp.n. (Myrsinaceae): uma nova espécie da Serra do Cipó, Minas Gerais, Brasil. Hoehnea 7: 41-46.

Jung, S.L. 1981. Flora Fanerogâmica da Reserva do Parque Estadual das Fontes do Ipiranga (São Paulo, Brasil): Myrsinaceae. Hoehnea 9: 88-91.

Jung-Mendaçolli, S.L. \& Bernacci, L.C. 1997. Flora Fanerogâmica da Ilha do Cardoso (São Paulo, Brasil): Myrsinaceae. Vol. 5, Pp. 81-98. In: M.M.R.F. Melo, F. Barros, S.A.C. Chiea, M. Kirizawa, S.L. JungMendaçolli \& M.G.L. Wanderley (ed.). Flora Fanerogâmica da Ilha do Cardoso. São Paulo, Imprensa Oficial.

Jung-Mendaçolli, S.L. \& Bernacci, L.C. 2001. Myrsinaceae da APA de Cairuçu, Parati (Rio de Janeiro, Brasil). Rodriguésia 52: 49-64.

Jung-Mendaçolli, S.L. \& Bernacci, L.C. \& Freitas, M.F. 2005. Myrsinaceae. Vol. 4. Pp. 279-300. In: M.G.L. Wanderley, G.J. Shepherd, T.S. Melhem, S.E. Martins, M. Kirizawa \& A.M. Giulietti (ed.). Flora Fanerogâmica do Estado de São Paulo. São Paulo, RiMa.

Mez, C. 1902. Myrsinaceae. Vol. 4, 236 (Heft 9). Pp. 1-437. In: A. Engler (ed.) Das Pflanzenreich. Leipzig, Verlag von Wilhelm Engelmann.

Miquel, F.A.G. 1856. Myrsineae. Vol. 10, Pp. 269-338. In: C.F.P. Martius, A.G. (ed.) Flora Brasiliensis. Lipsiae, Frid. Fleischer.

Pipoly, J.J. 1981. Contributions toward a monograph of Cybiantus (Myrsinaceae): I. subgenus Iteoides and the identity of Conomorpha loretensis. Brittonia 33: 493-497.

Pipoly, J.J. 1987. A systematic revision of the genus Cybiantus subgenus Grammadenia (Myrsinaceae). Memoirs of the New York Botanical Garden 43: 1-76.

Pipoly, J.J. 1993. Notes on Cybianthus subgenus Cybianthus (Myrsinaceae) in southeastern Brazil. Novon 3: 459-462.

Pipoly, J.J. \& Ricketson, J.M. 2006. New species of Cybianthus Martius (Myrsinaceae) from the Hylean/Andean Interface of Peru. Novon 16: $248-253$.

Ståhl, B. 1997. The relationships of Heberdenia bahamensis and $H$. penduliflora (Myrsinaceae). Botanical Journal of the Linnean Society 122: 315-333. 